Nova Southeastern University

From the SelectedWorks of Lee A Wilkinson, PhD

2007

\title{
Assessing treatment integrity in behavioral consultation
}

Lee A Wilkinson 


\title{
Assessing Treatment Integrity in Behavioral Consultation
}

\author{
Lee A. Wilkinson
}

\begin{abstract}
The trend in school psychology services is a shift from an emphasis on an assessment-based paradigm to one of consultation problem-solving and behavioral intervention. A critical component of consultationderived interventions and behavior change is treatment integrity. Treatment integrity (or fidelity) refers to the extent to which an intervention is implemented as intended (or planned). Although its importance has been acknowledged in the literature, this construct has largely been neglected in consultation research and practice. This article describes practical approaches for assessing and monitoring the integrity of treatments implemented during the problem-solving process. A treatment-monitoring interview (TMI) is proposed as an initial step towards developing a technology to assess and facilitate treatment integrity in behavioral consultation practice. Limitations, implications for practice, and future research directions are discussed.
\end{abstract}

Keywords: behavioral intervention, treatment integrity, treatment-monitoring interview, (TMI)

The role of consultation in school psychology is expected to expand significantly over the next decade as the field experiences a shift from an emphasis on assessment-related activities to an ecological and problem solving paradigm of practice (Sheridan \& Gutkin, 2000). Surveys consistently indicate that this indirect model of service delivery is one of the most preferred and valued professional activities of the school psychologist (Gilman \& Gabriel, 2004; Kratochwill \& Stoiber, 2000; Reschly, 2000). Legislative initiatives such as the Individuals with Disabilities Education Reform Act (IDEA '04) and No Child Left Behind Act (NCLB) are expected to provide further impetus and support for the expansion of problemsolving consultation and intervention-oriented services by school psychologists.

\section{Behavioral Consultation}

Decades of research have documented the effectiveness of consultation as a frame work for delivering services to children with a wide variety of learning and behavioral problems in general education settings (Gutkin, 1996; Kratochwill \& Stoiber, 2000). Of the several theoretical models available to practitioners (e.g., mental health, organizational, and behavioral), behavioral consultation (Kratochwill \& Bergan, 1990) is the most popular and frequently practiced type of school-based consultation. (Erchul \& Martens, 2002). The behavioral consultation model has received substantial empirical support in reviews, meta-analyses, and case studies (Bramlett \& Murphy, 1998; Kratochwill, Elliott, \& Busse, 1995; MacLeod, Jones, Somers, \& Havey, 2001; Medway \& Updyke, 1985; Sheridan, Welch, \& Orme, 1996; Wilkinson, 1997, 2003).

\section{Treatment Integrity}

Identifying an effective treatment is a necessary but inadequate condition for producing behavior change (Wickstrom, Jones, LaFleur, \& Witt, 1998). The success of intervention plans developed and implemented during behavioral consultation is largely dependent on the extent to which they are implemented as intended or planned by consultees (e.g., teachers, parents), or what has been termed treatment integrity (Gresham, 1989; Truscott, Richardson, Cohen, Frank, \& Palmeri, 2003). Treatment integrity (or fidelity) reflects the accuracy and consistency with which each component of the treatment or 
intervention plan is implemented. It is an important link between the use and effectiveness of interventions in school settings and a key aspect of scientific investigation (Elliott \& Busse, 1993). Treatment plans implemented with poor integrity make it difficult to draw accurate inferences about the relationship between an intervention and behavior change (Gutkin, 1993). In many consultation cases, absent or weak treatment effects might be the result of an intervention's poor integrity, despite its demonstrated empirical support (Cautilli, Tillman, Axelrod, Dziewolska, Hineline, 2006; Cautilli, RileyTillman, Axelrod, \& Hineline, 2005). According Gresham (1989), "Many failures in consultation and interventions probably can be attributed to the fact that intervention plans are not implemented as intended" (p. 137). Thus, it is essential that treatment integrity information be collected when implementing consultation-derived interventions in order to distinguish between ineffective treatments and potentially effective interventions implemented with poor integrity (Gresham, 1989; Gutkin, 1993).

\section{Treatment Integrity in Research and Practice}

Although the importance of treatment validity has been acknowledged in the literature, this construct has largely been ignored in research and practice (Erchul \& Shulte, 1996; Witt, Noell, LaFleur, \& Mortenson, 1996; Lane, Bocian, MacMillan, \& Gresham, 2004). Relatively few intervention studies have monitored or systematically assessed treatment integrity (Gresham, 1989; Gresham, 2004). For example, only $20 \%$ of behavioral intervention studies published in the Journal of Applied Behavior Analysis from 1968 to 1980 presented data concerning treatment integrity (Peterson, Homer, \& Wonderlich, 1982). Likewise, $14.4 \%$ of school-based and $16 \%$ of child-based behavioral intervention studies published in the Journal of Applied Behavior Analysis between the years 1980 to 1990 provided treatment integrity information (Gresham, Gansle, \& Noell, 1993; Gresham, Gansle, Noell, Cohen, \& Rosenblum, 1993). A survey of intervention articles published in three major learning disabilities journals from 1995 to 1999 found that only $18.5 \%$ of the studies measured and reported data on treatment integrity (Gresham, MacMillan, Beebe-Frankenberger, \& Bocian, 2000). Similarly, approximately 25\% of research articles published in the Journal of Applied Behavior Analysis from 1996 to 2000 reported treatment integrity measures (Progar, Perrin, DiNovi, \& Bruce, 2001). Most recently, a review of intervention studies conducted with children with autism published in recognized behavioral journals (e.g., Journal of Applied Behavior Analysis) between the years 1993-2004 found that just 18\% actually assessed and reported treatment integrity data (Wheeler, Baggett, Fox, \& Blevins, 2006).

Based on the existing literature, it seems clear that attention to treatment integrity is the exception rather than the rule (Gresham et al., 1993a). This apparent double standard in consultation research and practice is troubling. For example, practitioners are expected to give careful attention to the design and implementation of interventions, selection of outcome measures, and the accuracy with which the outcome data are collected (Lane et al., 2004). Yet, the same consideration is not given to the implementation of school-based interventions (Gresham et al., 2000). Consultants frequently assume that a consultee's good intentions and verbal agreement will result in fidelity to their intervention plans. Research also suggests that in a majority of cases, school psychologists either fail to monitor plans or do not include an evaluation component in their consultation practice. When evaluations are conducted, informal teacher verbal reports tend to be the most common form of outcome measure (Bramlett et al., 2002).

\section{Purpose}

While it seems reasonable to expect that behavioral consultation practice should pay more, not less attention to the assessment of treatment integrity, the model addresses this construct in no more than a cursory manner (Erchul and Shulte, 1996; Gutkin, 1993; Witt, Gresham, \& Noell, 1996). Although brief 
contacts are made with the consultee during treatment implementation, the traditional behavioral consultation process does not provide a structured method of monitoring treatment integrity (Kratochwill \& Bergan, 1990). The primary purpose of this article is to propose an expansion of the traditional behavioral consultation model that provides school-based consultants with a method of assessing and monitoring fidelity to intervention plans.

\section{Assessing Treatment Integrity}

There are several methods school psychologists can use to document the extent to which behavioral interventions agreed upon during consultation are being implemented as intended by the change agent (e.g., teacher or parent). Although systematic observation is the most direct means of assessing treatment integrity, this procedure is vulnerable to reactivity effects and tends to be a labor intensive activity which is not always feasible given the time constraints and logistical problems encountered in real world school settings (Wilczynski, Mandal, \& Fuslier, 2000). There are, however, less direct methods that can be utilized to assess and monitor the fidelity of treatment plans implemented in consultation practice. They include (a) consultee self-reporting, (b) permanent products, (c) behavioral interviews and (d) feedback from consultants (Lane et al., 2004).

\section{Self-Reports}

Self-reports of treatment integrity involve having consultees report the extent to which they have implemented each component of the intervention. Table 1 provides an example of how treatment integrity can be assessed using a self-report method for a cognitive behavior modification intervention. As shown, the teacher reported that five out of six self-management intervention components were implemented on Monday, Tuesday, and Friday, resulting in a daily integrity rating of $83 \%$, (b) three out of six components were applied on Wednesday and Thursday, indicating 50\% integrity each day, and (c) components one and two were implemented with $100 \%$ fidelity over the course of the week. In contrast, components five and six were implemented with only $20 \%$ accuracy. Although consultee self-reports can provide school psychologists with important treatment integrity data, not all interventions are well-suited to this assessment method. Moreover, this technique may overestimate the level of treatment fidelity and produce inaccurate reports (Gresham et al., 2000).

Table 1. Example of a Treatment Integrity Checklist

\section{Treatment Integrity Checklist}

\section{Cognitive Behavior Modification Plan}

Student: Teacher: Grade Level:

Directions: Please complete this form each day. Record a "Y" if the component was implemented; if the component was not implemented, record an "N".

\section{Intervention components}

\section{Day}

$\begin{array}{lllll}\mathbf{M} & \mathbf{T} & \mathbf{W} & \mathbf{T} & \mathbf{F}\end{array}$


1. Reviewed behavior goal(s) with student.

2. Cued student to self-monitor and record response.

3. Compared ratings with student.

4. Provided verbal praise for accurate ratings.

5. Gave reward when behavioral goal was met.

6. Sent behavior recording form to parent.
$\begin{array}{lllll}\mathrm{Y} & \mathrm{Y} & \mathrm{Y} & \mathrm{Y} & \mathrm{Y}\end{array}$

$\begin{array}{lllll}\mathrm{Y} & \mathrm{Y} & \mathrm{Y} & \mathrm{Y} & \mathrm{Y}\end{array}$

$\begin{array}{lllll}\mathrm{Y} & \mathrm{Y} & \mathrm{N} & \mathrm{Y} & \mathrm{Y}\end{array}$

$\begin{array}{lllll}\mathrm{Y} & \mathrm{Y} & \mathrm{Y} & \mathrm{N} & \mathrm{Y}\end{array}$

$\begin{array}{llllll}\mathrm{Y} & \mathrm{N} & \mathrm{N} & \mathrm{N} & \mathrm{Y}\end{array}$

$\begin{array}{llllll}\mathrm{N} & \mathrm{Y} & \mathrm{N} & \mathrm{N} & \mathrm{N}\end{array}$

Note. Adapted from "Monitoring Treatment Integrity: An Alternative to the "Consult and and Hope' Strategy in School-Based Behavioral Consultation," by Lee A. Wilkinson, 2006, School Psychology International, 27, p. 431. Copyright 2006 by Sage Publications. Adapted with permission.

\section{Permanent Products}

Permanent product assessment refers to a product that is generated as the result of an intervention and evaluated to determine the extent to which a corresponding component was implemented as intended (Lane et al., 2004). To illustrate, a permanent product could be used to monitor the treatment integrity of the intervention used in the previous self-report example (Table 1). In this instance, treatment integrity would be assessed by examining the student's self-monitoring recording form and/or home-school note each day to determine fidelity to this intervention component. Another example might involve an intervention to increase academic productivity. Classroom worksheets or assignments would be collected and evaluated by the consultant to determine accuracy and the level of task completion. Permanent products have the advantage of being less time consuming, more efficient, less reactive and potentially more accurate than other assessment methods (Gresham et al., 2000; Lane et al., 2004).

\section{Interview and Performance Feedback}

Research indicates that a combination of treatment monitoring and performance feedback can increase the level of treatment implementation and enhance student behavioral outcomes (Jones, Wickstrom, \& Friman, 1997; Mautone, Luiselli, \& Handler, 2006; Mortenson \& Witt, 1998; Noell et al., 2005; Noell, Duhon, Gatti, \& Connell, 2002; Noell, Witt, LaFleur, Mortenson, Ranier, \& LeVelle, 2000; Noell, Witt, Gilbertson, Ranier, \& Freeland, 1997; Witt, et al., 1997). Expanding the traditional behavioral consultation model to include a structured treatment monitoring stage, rather than only brief informal contacts, should be an effective means by which to provide valuable performance feedback and supportive assistance to consultees. (Codding, Feinberg, Dunn, \& Pace, 2005; Knoff, Hines, \& Kromery, 1995; Wilkinson, 2005).

Table 2 depicts the stages and objectives of the expanded behavioral consultation model. The primary objective of the treatment monitoring interview (TMI) is to increase the strength of the treatment plan by providing direct support and performance feedback (Butler, Weaver, Doggett, \& Watson, 2002). A semi-structured interview (see Appendix) is conducted with the consultee(s) to (a) review the student's 
behavioral progress, (b) identify barriers or obstacles to plan implementation, and (c) determine the need for plan modification. A performance feedback session is then conducted to (a) analyze treatment integrity data (permanent products and self-report checklists), (b) provide positive praise for completed components and corrective feedback for steps omitted or incorrectly implemented, (c) address consultee questions and concerns, (d) determine the need for further training or support, and (e) reaffirm the consultee's commitment to implementing the plan.

Table 2. The Expanded Behavioral Consultation Model

\section{Problem Identification Interview (PII)}

1. Define the target problem(s) in observable terms.

2. Identify important environmental conditions that influence behavior.

3. Agree on a goal for behavioral change.

4. Establish a procedure for data-collection.

\section{Problem Analysis Interview (PAI)}

1. Analyse baseline data.

2. Identify antecedent, consequent, and sequential conditions.

3. Design a treatment plan strategy.

\section{Treatment (Plan) Implementation}

1. Implement treatment plan.

2. Continue data-collection procedure.

\section{Treatment Monitoring Interview (TMI)}

1. Increase fidelity to the intervention plan.

2. Review permanent products and self-reports.

3. Provide data-based feedback and support.

4. Determine need for additional training.

\section{Treatment Evaluation Interview (TEI)}

1. Evaluate treatment plan effectiveness.

2. Assess social validity and consultant effectiveness.

3. Discuss continuation, modification, or termination of the plan.

Note. Adapted from 'Using behavioral consultation to reduce challenging behavior in the classroom,' by Lee A. Wilkinson, 2003, Preventing School Failure, 47, p. 101. Copyright 1993 by Heldref Publications. Adapted with permission. 
Treatment Monitoring Interview (TMI)

Child's Name:

Teacher's Name:

School:

The consultant should question and/or comment on all of the following:

OPENING SALUTATION

GENERAL STATEMENT/QUESTION REGARDING PLAN IMPLEMENTATION

a. How successful were you in implementing the intervention as discussed during our last meeting? Please describe.

Record responses:

b. Is the plan producing the desired change in target behavior? What changes have you observed in the student's academic/behavioral performance (positive or negative)?

Record Responses:

\section{OBSTACLES TO PLAN IMPLEMENTATION}

a. Have you encountered any barriers to implementing the plan? If so, please specify. What can we do to overcome them? 
Record Responses:

b. Does the plan need to be altered or changed in some way in order to effective? If yes, how? Will revising the plan help you to implement it more consistently?

Record Responses:

\section{DATA BASED (PERFORMANCE) FEEDBACK}

a. Let's look at the data you've collected so far so we can evaluate the student's progress (Summarize/graph student performance data and evaluate permanent products).

Record Responses:

b. Let's review your treatment plan (self-report) ratings and discuss any of the steps you had difficulty implementing (provide praise for completed components). If you are having problems, do you need more training or assistance in order to implement the plan? If so, please describe.

Record Responses:

NEXT APPOINTMENT

When can we meet again to discuss the data and determine whether the plan has been effective?

Date: 
Day:

Time:

\section{Implications for Consultation Practice}

Research challenges the assumption that treatment integrity is being assessed and monitored in behavioral consultation and intervention practice (Jones et al., 1997). Knowing that an intervention is effective and understanding how to use it does not guarantee its accurate implementation and use (Wickstrom et al., 1998). Likewise, including elements of rational persuasion (e.g., discussing the importance of the intervention and addressing possible objections) in brief meetings with consultees are inadequate to support consistent treatment implementation (Truscott et al., 2003). Expanding the behavioral consultation model to include a treatment monitoring interview (TMI) offers consultants a practical and effective method of monitoring treatment integrity. Practitioners and researchers will find the interview procedures and objectives presented in this article helpful in coordinating the intervention process and providing efficient follow-up on treatment plan implementation. Treatments implemented with poor integrity can prompt consultants to make adjustments to treatment plans and expend greater time and effort on the plan implementation stage of consultation (Gresham et al., 1993). Information obtained during the TMI can also be used to determine whether additional procedures or support are needed for training consultees to implement the intervention properly and to assist in generalization of consultation-based skills (Tillman, 2000).

\section{Limitations}

While including a formal TMI in the behavioral consultation model holds promise for enhancing treatment integrity, there are limitations inherent in this approach. For example, the consultation process conceptualized here is likely to be a labor-intensive activity. The four consultation interviews require a substantial investment of time from both the consultant and consultee(s). This high level of active participation and commitment required by the expanded $\mathrm{BC}$ model might be unrealistic for many educators given their classroom schedules and limited planning time (Wilczynski et al., 2000). Likewise, more frequent feedback than that provided by the TMI may be required to sustain treatment implementation, further increasing logistic demands (Jones et al., 1997; Noell et al., 2005). From a costbenefit perspective, procedural aspects of $\mathrm{BC}$ may need adjustment to accommodate these empirical barriers. For example, it might be necessary to streamline the process and reduce duplication to improve efficiency. Another important limitation involves the use of consultee self-reports to monitor treatment plan implementation. This method can be influenced by social desirability and may inflate estimated levels of integrity when compared to direct observation and permanent product data (Gresham et al., 2000; Lane et al., 2004).

\section{Research Directions}

Empirically validated procedures for assessing and improving treatment implementation are not well developed and remain a critical research need. Future research should investigate adaptation of the TMI to consultation practice to determine its effectiveness in facilitating treatment integrity. Additionally, research should examine the agreement between direct observation and self-reports/permanent products to evaluate the robustness of these indirect assessment methods. It is also unclear what levels of treatment integrity are necessary to ensure positive outcomes. Treatment integrity and student performance might be measured at varying points during treatment implementation to determine the extent to which continued direct support and performance feedback is necessary to maintain an adequate level of treatment integrity 
(Progar et. al., 2001). Lastly, research should include the experimental manipulation of both treatment acceptability and integrity as dependent variables to more fully understand their roles in behavior change (Noell et al., 2002).

\section{Conclusion}

The fidelity with which consultative-derived intervention plans are implemented with students is an essential component of consultation practice (Gresham et al., 2000). As problem-solving consultation is more widely adopted by the school psychology community, practitioners must recognize the importance of treatment integrity as a defining feature of successful intervention (Erchul \& Schulte, 1996). Expanding the behavioral consultation model to include the treatment monitoring interview (TMI) described in this article represents an initial step in developing the structure and technology necessary to address one of the most critical aspects of school-based consultation practice: ensuring the accurate implementation of our behavioral interventions.

\section{References}

Bramlett, R. K. \& Murphy, J. J. (1998). School psychology perspectives on consultation: Key contributions to the field, Journal of Educational and Psychological Consultation, 9, 29-55.

Bramlett, R. K., Murphy, J. J., Johnson, J., Wallingsford, L. \& Hall, J. D. (2002). Contemporary practices in school psychology: A national survey of roles and referral problems. Psychology in the Schools, 39, 327-335.

Butler, T. S., Weaver, A. D., Doggett, R. A., \& Watson, T. S. (2002). Countering teacher resistance in behavioral consultation: Recommendations for the school-based consultant. The Behavior Analyst Today, 3, 282-288.

Cautilli, J., Tillman, T. C., Axelrod, S., Dziewolska, H., \& Hineline, P. (2006). Resistance is not futile: An experimental analogue of the effects of consultee "resistance" on the consultant's therapeutic behavior in the consultation process: A replication and extension. International Journal of behavioral and Consultation Therapy, 3, 362-373.

Cautilli, J., Riley-Tillman, T., Axelrod, S., \& Hineline, P. (2005). Current behavioral models of client and consultee resistance: A critical review. International Journal of Behavioral Consultation and Therapy, 1, 147-164.

Codding, R. S., Feinberg, A. B., Dunn, E. K. \& Pace, G. M. (2005). Effects of immediate performance feedback on implementation of behavior support plans. Journal of Applied Behavior Analysis, 38, 205-219.

Elliott, S. N. \& Busse, R. T. (1993). Effective treatments with behavioral consultation. In J. E. Zins, T. R. Kratochwill, \& S. N. Elliott (Eds.), Handbook of consultation services for children: Applications in educational and clinical setting (pp.179-203). San Francisco: Jossey-Bass.

Erchul, W. P., \& Martens, B. K. (2002). School consultation: Conceptual and empirical bases of practice (2nd ed.). New York: Kluwer Academic/Plenum Publishers.

Erchul, W. P. \& Schulte, A. C. (1996). Behavioral consultation as a work in progress: A reply to Witt, Gresham, and Noell. Journal of Educational and Psychological 
Consultation, 7, 345-354.

Gilman, R. \& Gabriel, S. (2004). Perceptions of school psychological services by educational professionals: Results from a multi-state survey pilot study. School Psychology Review, 33, 271-286.

Gresham, F. M. (1989). Assessment of treatment integrity in school consultation and prereferral Intervention. School Psychology Review, 18, 37-50.

Gresham, F. M. (2004). Current status and future directions of school-based behavioral interventions. School Psychology Review, 33, 326-343.

Gresham, F. M., Gansle, K. A. \& Noell, G. H. (1993a). Treatment integrity in applied behavior analysis with children. Journal of Applied Behavior Analysis, 26, 257263.

Gresham, F. M., Gansle, K. A., Noell, G. H., Cohen, S. \& Rosenblum, S. (1993b). Treatment integrity of school-based behavioral intervention studies: 1980-1990 School Psychology Review, 22, 254-272.

Gresham, F. M., MacMillan, D., Beebe-Frankenberger, M. E. \& Bocian, K. M. (2000). Treatment integrity in learning disabilities intervention research: Do we really know how treatments are implemented? Learning Disabilities Research and Practice, 15, 198-205.

Gutkin, T. B. (1993). Conducting consultation research. In J. E. Zins, T. R. Kratochwill, \& S. N. Elliott (Eds.), Handbook of consultation services for children: Applications in educational and clinical settings (pp. 227-248). San Francisco: Jossey-Bass

Gutkin, T. B. (1996). Core elements of consultation service delivery for special service personnel: Rationale, practice, and some directions for the future. Remedial and Special Education, 17, 333-340.

Jones, K. M., Wickstrom, K. F. \& Friman, P. C. (1997). The effects of observational feedback on treatment integrity in school-based behavioral consultation. School Psychology Quarterly, 12, 316-326.

Knoff, H. M., Hines, C. V. \& Kromrey, J. D. (1995). Finalizing the consultant effectiveness scale: An analysis and validation of the characteristics of effective consultants. School Psychology Review, 24, 480-496.

Kratochwill, T. R. \& Bergan, J. R. (1990). Behavioral consultation in applied settings: An individual guide. New York: Plenum.

Kratochwill, T. R., Elliott, S. N. \& Busse, R. T. (1995). Behavioral consultation: A five year evaluation of consultant and client outcomes. School Psychology Quarterly, 10, 87-117.

Kratochwill, T. R. \& Stoiber, K. C. (2000). Uncovering critical research agendas for 
school psychology: Conceptual dimensions and future directions. School Psychology Review, 29, 591-603.

Lane, K. L., Bocian, K. M., MacMillan, D. L. \& Gresham, F. M. (2004). Treatment integrity: An essential-but often forgotten-component of school-based interventions. Preventing School failure, 48, 36-43.

MacLeod, I. R., Jones, K. M., Somers, C. L. \& Havey, J. M. (2001). An evaluation of the effectiveness of school-based behavioral consultation. Journal of Educational and Psychological Consultation, 12, 203-216.

Mautone, J. A., Luiselli, J. K., \& Handler, M. W. (2006). Improving implementation of classroom instruction through teacher-directed behavioral consultation: A single case demonstration. International Journal of Behavioral and Consultation Therapy, 3, 432-438.

Medway, F. J. \& Updyke, J. F. (1985). Meta-analysis of consultation outcome studies. American Journal of Community Psychology, 13, 489-505.

Mortenson, B. P., \& Witt, J. C. (1998). The use of weekly performance feedback to increase teacher implementation of a prereferral intervention. School Psychology Review, 27, 613-627.

Noell, G. H., Duhon, G. J., Gatti, S. L. \& Connell, J. E. (2002). Consultation, follow-up, and implementation of behavior management interventions in general education. School Psychology Review, 31, 217-234.

Noell, G. H., Witt, J. C., Gilbertson, D. N., Rainer, D. D. \& Freeland, J. T. (1997). Increasing teacher Intervention implementation in general education settings through consultation and performance feedback. School Psychology Quarterly, 12, 77-88.

Noell, G. H., Witt, J. C., LaFleur, L. H., Mortenson, B. P., Ranier, D. D. \& LeVelle, J. (2000). A comparison of two follow-up strategies to increase teacher intervention implementation in general education following consultation. Journal of Applied Behavior Analysis, 33, 271-284.

Noell, G. H., Witt, J. C., Slider, N. J., Connell, J. E., Gatti, S. L., Williams, K. L. et al. (2005). Treatment implementation following behavioral consultation in schools: A comparison of three follow-up strategies. School Psychology Review, 34, 87-106.

Peterson, L., Homer, A. L. \& Wonderlich, S. A. (1982). The integrity of independent variables in behavior analysis. Journal of Applied Behavior Analysis, 15, 477-492.

Progar, P. R., Perrin, F. A., DiNovi, B. J., \& Bruce, S. S. (2001). Treatment integrity: Some persistent concerns and new perspectives. The Behavior Analyst Today, 2, 28-32. 
Reschly, D. J. (2000). The present and future status of school psychology in the United States. School Psychology Review, 29, 507-522.

Sheridan, S. M. \& Gutkin, T. B. (2000). The ecology of school psychology: Examining and changing our paradigm for the 21 st century'. School Psychology Review, 29, 485-502.

Sheridan, S. M., Welch, M. \& Orme, S. F. (1996). Is consultation effective? A review of outcome research. Remedial and Special Education, 17, 341-354.

Tillman, T. C. (2000). Generalization programming and behavioral consultation. The Behavior Analyst Today, 1, 30-34

Truscott, S. D., Richardson, R. D., Cohen, C., Frank, A. \& Palmeri, D. (2003). Does rational persuasion influence potential consultees? Psychology in the Schools, 40, 627-640.

Watkins, M. W., Crosby, E. G. \& Pearson, J. L. (2001). Role of the school psychologist: perceptions of school staff. School Psychology International, 22, 64-73.

Wheeler, J. J., Baggett, B. A., Fox, J., \& Blevins, L. (2006). Treatment integrity: A review of intervention studies conducted with children with autism. Focus on Autism and Other Developmental Disorders, 21, 45-54.

Wickstrom, K. F., Jones, K. M., LaFleur, L. H. \& Witt, J. C. (1998). An analysis of treatment integrity in school-based behavioral consultation. School Psychology Quarterly, 13, 141-154.

Wilczynski, S. M., Mandal, R. L. \& Fusilier, I. (2000). Bridges and barriers in behavioral consultation. Psychology in the Schools, 37, 495-504.

Wilkinson, L. A. (1997). School-based behavioral consultation: delivering treatment for children's externalizing behavior in the classroom. Journal of Educational and Psychological Consultation, 8, 255-276.

Wilkinson, L. A. (2003). Using behavioral consultation to reduce challenging behavior in the classroom. Preventing School Failure, 47, 100-105.

Wilkinson, L. A. (2005). Bridging the research-to-practice gap in school-based consultation: An example using case studies. Journal of Educational and Psychological Consultation.

Wilkinson, L. A. (2006). Conjoint behavioral consultation: An emerging and effective model for developing home-school partnerships. International Journal of Behavioral Consultation and Therapy, 2, 225-239.

Witt, J. C., Gresham, F. M. \& Noell, G. H. (1996). What's behavioral about behavioral consultation? Journal of Educational and Psychological Consultation, 7, 327-344.

Witt, J. C., Noell, G. H., LaFleur, L. H. \& Mortenson, B. P. (1997). Teacher usage of 
interventions in general education: Measurement and analysis of the independent variable. Journal of Applied Behavior Analysis, 30, 693-696.

Author Contact Information:

Lee A. Wilkinson, $\mathrm{PhD}$,

7708 Red River Road,

West Palm Beach, FL 33411.

E-mail: lawilkinson@bellsouth.net

\section{Author's note}

Lee A. Wilkinson, Ed.D., Ph.D. NCSP is a nationally certified school psychologist and adjunct professor at Capella University and Nova Southeastern University. His research and professional interests include behavioral consultation, evidence-based interventions in school psychology practice, and issues related to inclusive education.

\section{Advertisement}

\section{The Behavioral Development Bulletin}

BAO is proud to announce the latest addition to our family of free online journals, The Behavioral Development Bulletin. The Behavioral Development Bulletin is the official journal of the Behavioral Development Special Interest Group of the Association for Behavior Analysis (ABA).

The BDB journal has been previously published in hard copy format for several years and is now available to readers in electronic format. All past issues will soon be archived and available online.

The BDB journal is especially relevant to behavior analysts who study the developmental processes responsible for behavior changes and their progressive organization. The BDB journal hopes to provide answers by looking at the biological and environmental factors that affect behavioral development, while maintaining primarily interest in the role of environmental contingencies in behavior change.

A link to the BDB journal is available at the BAO homepage: http://www.behavior-analystonline.org, or you may go directly to the BDB journal homepage: http://www.behavioraldevelopment-bulletin.com

We hope you will enjoy the BDB journal!

Joe Cautilli/BAO Journals 